\title{
Secondary Mycobacterium avium complex (MAC) pulmonary disease
}

Rachel N. Plotinsky, Elizabeth A. Talbot, C. Fordham von Reyn

\section{Source}

Rachel N. Plotinsky, Elizabeth A. Talbot, C. Fordham von Reyn. (2013). Proposed

Definitions for Epidemiologic and Clinical Studies of Mycobacterium avium Complex

Pulmonary Disease. PLOS ONE, vol. 8 (11), e77385.

Disease occurring in a patient with known antecedent lung disease at time of MAC diagnosis such chronic obstructive pulmonary disease, asthma, or pre-existing bronchiectasis. 